\title{
MIRARSE EN LA VÍCTIMA: RECONFIGURACIÓN DE LA CULPABILIDAD MORAL
}

\author{
XABIER ETXEBERRIA MAULEON \\ Universidad de Deusto
}

\begin{abstract}
RESUMEN: En este estudio se defiende que la culpabilidad, frente a sus numerosos críticos, es una categoría imprescindible para la ética que se hace cargo de la realidad del mal. Pero, a la vez, se postula que solo se expresa adecuadamente si es vivida por el culpable mirándose en la víctima. Es algo que tienden a ignorar tanto los que la critican como los que la defienden. Cuando, en cambio, se percibe la culpabilidad con esta focalización, todo queda reconfigurado: el centramiento en la subjetividad del que obró mal, el sentimiento de culpa, la relación entre las variables de la culpa, la responsabilidad, el arrepentimiento. Se muestra así que la culpabilidad vivida con autenticidad hace justicia a la víctima y, concomitantemente, es vía de sanación para el victimario.
\end{abstract}

PALABRAS CLAVE: culpabilidad; responsabilidad; arrepentimiento; víctimas.

\section{From the mirror of the victim: Reconfiguring moral guilt}

ABSTRACT: In this study it is argued that, against its many critics, guilt is an essential category in the ethical area that takes responsibility of the reality of evil. But, at the same time, it is postulated that guilt expresses itself properly only if it is experienced by the guilty person through the mirror of the victim. This is an aspect usually ignored by both its critics and those who advocate it. However, when guilt is perceived under this light, everything is reconfigured: the focus on the wrongdoer's subjectivity, the guilty feeling, the relationship between the variables of guilt, responsibility and repentance. From the reconsideration resulting from this point of view, guilt experienced with authenticity does justice to the victim and, concomitantly, is a way of healing for the perpetrator.

KEY WORDS: guilt, responsibility, repentance, victims.

INTRODUCCIÓN: LA CULPABILIDAD, UNA CATEGORÍA BAJO SOSPECHA

No es fácil encontrar hoy reflexiones que defiendan la validez y relevancia moral de las categorías de «culpa», «culpabilidad» — como cualidad de quien tiene culpa- y «arrepentimiento». Al contrario, abundan las críticas contundentes a ellas que, además, reflejan «climas sociales» de opinión que las rechazan. Aunque con frecuencia son argumentalmente simplificadoras, no debe ignorarse que tienen tras de sí pensadores de peso, como Spinoza, Nietzsche o Freud. Dado que pretendo reivindicarlas como imprescindibles para la ética, conviene que comience haciéndome cargo de esas objeciones. Es algo que dará pie a que presente, en contraposición con ellas, el enfoque con el que pienso que debe ser asumida la culpa y sus categorías derivadas: el que pide al culpable que ponga el foco referencial de sus vivencias en su víctima.

En la literatura divulgativa, en general en los entornos de la psicología, suele criticarse el «sentimiento de culpa» por estas razones: 1) reprime la expresión del deseo, al que se opone, y, por tanto, las posibilidades de iniciativa ligadas a él; 2) nos aliena: dado que nos sentimos culpables porque alguien nos acusa - aunque hayamos interiorizado su autoridad—, nos extrañamos en ese alguien, 
que pasa a regular nuestra espontaneidad; 3) es un mecanismo de dominación y manipulación en su ligazón constitutiva con el temor al castigo, asentado a través de nuestra socialización; 4) cuando la vivencia de culpa es interiorizada, se expresa como masoquismo: dado que he faltado a la norma, tengo que autotorturarme, con mis propios sentimientos e incluso con acciones; 5) todo lo cual acarrea quiebra grave de la autoestima, condición necesaria para la consistencia personal y la iniciativa; 6) además, con la fijación obsesiva en el pasado que supone la culpabilidad, alienta la ilusión imposible de cambiarlo, de que fuera de otra manera, y bloquea la orientación al futuro ${ }^{1}$. Suele añadirse con frecuencia que ello es expresión y fruto de la tradición judeo-cristiana que, en estas cuestiones, habría prevalecido frente a la griega, lo que implica una doble critica: al contenido de dicha tradición y a su pretensión de que lo que es una categoría religiosa sirva para la sociedad civil, por cierto, ampliamente secularizada, al menos en el «mundo occidental». Si, además, se acude a la tradición oriental (budista, hinduista...) tiende a destacarse que inclina oportunamente a no plantearse respecto al pasado culpa ni arrepentimiento, a no motivarnos por lo que fuimos sino por lo que somos en cada momento presente, conscientes de la relatividad de nuestra identidad individual.

Aunque las críticas se dirigen directamente a las vivencias de culpabilidad, en realidad afectan a la culpa en sí, por ser vista como inevitable generadora de ellas. Se pide, por eso, que sea desterrada. Evidentemente, de algún modo hay que hacerse cargo de lo que supuso daño en el pasado o no funcionó bien, así como de los límites que impone lo real; pero, casi unánimemente, se propone otra categoría que la sustituya: la de una responsabilidad que, afirmada en el presente, se orienta decididamente al futuro; arrepentimiento y perdón quedan así desechados.

Hay que asumir que estas críticas remiten, con evidencia fáctica, a vivencias reales de los sujetos, desvelando así las potencialidades patológicas de la culpabilidad. Pero deducir de ello que la culpa y su vivencia abierta al arrepentimiento se reducen a ellas, es caer en la falacia de la composición, tomar la parte por el todo. O si se quiere, solo podría concluirse en ello si se muestra que ambas categorías no pueden ser otra cosa que morbosidad destructiva. Lo que es puesto en cuestión desde la constatación de que también hay hechos que muestran que se dan vivencias de culpabilidad sanadoras. Constatación que debería impulsar el reto social y educativo no de desterrar la culpa ni los sentimientos correspondientes, sino de reducir todo lo posible las vivencias patológicas y fomentar las liberadoras.

Con todo, la mejor manera de refutar las objeciones antedichas no es mostrar meramente la realidad de otros modos de vivencias personales, pues podría encaminarnos a la inadecuada lógica del cálculo y, especialmente, a

1 Hay investigaciones psicológicas que destacan lo positivo para la persona y la sociedad de la propensión a sentirse culpable (COHEN, PANTER y Turan, 2012), pero no parece que sean frecuentes. 
considerar que lo que está en juego es únicamente la subjetividad del culpable. Se precisa replantear la perspectiva, situarnos en un enfoque que se muestre más adecuado para definir la culpa y su vivencia auténtica, y comprobar así si es, per se, no solo positiva sino moralmente necesaria. Pues bien, pienso que esta perspectiva diferente es la que se plasma en que el culpable defina su culpa mirándola desde la víctima que la sufre, y elaborándola subjetivamente ante ella - y con ella cuando sea posible—. Es la propuesta que me propongo desarrollar en este trabajo.

\section{Elaborar LA CUlPA MIRÁNDOSE EN LA VÍctima}

Comienzo por precisar la nueva perspectiva por contraposición a la implicada en las objeciones. El rechazo de la culpa que se hace en estas se propone por la vía del rechazo del sentimiento de culpa por ser considerado en sí destructor de quien se percibe culpable. Eso supone que se contempla una culpabilidad decisivamente autocentrada en el yo que la siente. Ahora bien, la culpa objetivamente sustentada remite a una acción que es moralmente mala porque causa un daño injusto a una víctima; hay un des-centramiento del yo intrínseco a ella que no aparece en las críticas, que se formulan como si la víctima no existiera. Pues bien, este des-centramiento es fundamental para elaborar bien la culpa; sin él ignoramos algo decisivo.

Es cierto que, no como algo externo, puede aducirse que las objeciones sí hablan de una víctima: el propio sujeto "victimado» por su vivencia de culpa. Ahora bien, tal como lo presentan, es víctima por una elaboración psíquica inadecuada, inducida por socialización, de un acontecimiento personal. Quizá en ello haya culpa de otros, que tendrán que asumirla, pero no de ella. Lo cual reclama en sí no propiamente rechazar la culpa como tal, sino alentar un adecuado discernimiento que liberará estrictamente del sentimiento subjetivo infundado de culpabilidad — nada más y nada menos—. Es cierto que en el enfoque kantiano cabe que alguien se desdoble en victimario y víctima de sí mismo: cuando con lucidez, intencionalidad y voluntariedad se autoinstrumentaliza en sentido fuerte. Aquí sí podría plantearse que hay culpa, y cabría aplicar a esta situación algunas de las reflexiones que iré haciendo. Pero no es esto lo que se considera en las objeciones y no es lo común en la culpa, por lo que priorizaré la circunstancia en la que la víctima es externa al sujeto victimador.

En realidad, en las objeciones sí hay en juego algo externo al que vive la culpabilidad: las normas que considera que ha quebrantado. Pero en los ejemplos que se ponen se trata en general de imperativos que, o no tienen consistencia moral, o son prescripciones estrictamente religiosas no universalizables ( «obedece siempre a tu marido», "no te masturbes», "cumple tal precepto de culto»"). Por cierto, suelen ser presentadas como puramente externas al sujeto y per se violentadoras de él, lo que, en realidad, debería llevar propiamente a 
rechazar ese tipo de leyes, no la culpa en sí. En cualquier caso, y dejando de lado esta cuestión, considero que la referencia paradigmática y universalizable para la culpabilidad tiene que ser la normatividad de los derechos humanos ${ }^{2}$, en la que la culpa supone la violación de ellos, y esta, a su vez y de nuevo, implica una víctima, en cuya dignidad está precisamente sustentada la validez de tal normatividad. Lo que significa que para la ética en el centro está la persona -la persona víctima cuando hay culpa-, no la ley.

Situándonos en esta normatividad resulta manifiesto que la más clara violación de los derechos humanos es el asesinato, por lo que lo tendré como referencia prioritaria para describir la culpa. Se trata de una referencia «ejemplar», esto es, no pretendo diluir la relevancia de otras violaciones, sino que propongo que la culpabilidad de todas ellas sea vista — con los necesarios acomodos- a la luz de lo que en él se nos muestra. Incluso, cuando se precise, contemplaré que el asesinato está alentado por motivaciones políticas, a fin de que aparezcan otras variables significativas ${ }^{3}$.

Podría aducirse que estas críticas son injustas con las objeciones que estoy considerando, que en ellas hay presencia implícita de las víctimas cuando se reclama responsabilidad ante los daños pasados. Pero esto no está nada claro. Ilustro mis reservas con un ejemplo tomado de la realidad. Dos comandos terroristas de tres personas cada uno reciben la orden de colocar una bomba en los bajos de sendos coches para que estallen al ser puestos en marcha y maten a sus ocupantes; uno cumple el objetivo y mata a tres personas, mientras que los componentes del otro manipulan inadecuadamente la bomba cuando la están colocando y les estalla, causando la muerte a los tres. Si la responsabilidad es alternativa a la culpa que mira con juicio moral al pasado, y considera únicamente hacer frente en lo posible a los daños causados, las seis víctimas deben recibir la misma consideración (de hecho, es lo que los terroristas proponen cuando piden negociaciones para el cese de la violencia). Si nuestra intuición moral nos dice que la justicia reclama una distinción entre víctimas (de hecho, es lo que piden las víctimas allegadas a los que han sufrido el atentado), entonces esa mera responsabilidad ya no vale, tendrá que dar paso a una que asume también la culpa, condicionando con ello el modo de afrontar el daño. Considero por mi parte que esa intuición es certera, que, por tanto, empuja a distinguir entre el sentido genérico de víctima — quien sufre por la causa que sea, humana o no humana- y su sentido moral e interpersonal — quien sufre por una iniciativa injusta de otro ser humano-. La víctima a

\footnotetext{
2 Se aborda esta justificación en ETXEBERRIA (2012)

3 La motivación más inmediata de este escrito ha sido la necesidad de fundamentar y desarrollar un concepto de culpa, en sí bajo sospecha, manifiestamente necesario al abordar la justicia debida a las víctimas de la violencia terrorista y al incentivar iniciativas que contemplen en el horizonte cuestiones como el arrepentimiento. Respecto a esto último son un ejemplo los encuentros restaurativos entre victimarios de ETA y sus víctimas (Ríos, 2015; ETXEBERRIA, 2013). Estos trasfondos motivacionales pueden encontrarse también ante otras violencias de motivación política, como las que se dan en el conflicto violento colombiano.
} 
la que remite la culpa es siempre esta víctima moral. La referencia a tal culpa aparece entonces como condición de posibilidad de justicia hacia ella; lo cual no impide, como defenderé también, que el culpable elabore de tal modo su culpabilidad que suponga para él un proceso de sanación.

Con estas consideraciones lo que propongo en definitiva es, según voy adelantando, re-focalizar el acercamiento a la problemática de la culpa y a su elaboración por el culpable. El foco primario debe estar en la víctima que la acción culposa ha causado, debiendo subordinarse a él el foco de la vivencia subjetiva. Pretendo mostrar que esto es profundamente revelador y que va al corazón de lo que la culpabilidad es en su autenticidad.

Curiosamente, es muy difícil encontrar no digo ya esta perspectiva sino huellas de ella, en los pensadores que se han ocupado de la culpa (sí en quienes, más recientemente, abordan el tema del perdón, ante el que este texto se quedará a las puertas). Es normal que esté ausente en los críticos de la culpa ya citados, como Spinoza (1987), Nietzsche (1994) o Freud (1980). Pero tampoco está presente en quienes defienden con firmeza la noción de culpabilidad, como Kant (1989), nada propenso a ex-culpar: el tribunal de la conciencia que se constituye internamente en nosotros para juzgar nuestros actos e in-culparnos, tiene como referencia expresa únicamente la legislación moral del legislador autónomo que somos (podría suponerse implícita la referencia a potenciales víctimas en el imperativo de humanidad, pero lo explicitado es el respeto a la ley). No lo está tampoco en Schopenhauer cuando analiza la imputabilidad culposa y la correspondiente responsabilidad desde la discutible tesis de que «el hombre hace siempre lo que quiere y lo hace, sin embargo, necesariamente» (Schopenhauer, 1993: 128). Ni se encuentra en quienes, como Scheler (2007), se muestran a favor de una positiva elaboración de la culpa que, mediando el arrepentimiento, incluya la sanación del culpable; o en quienes como Ricoeur, hacen finos estudios sobre la evolución del pecado «ante Dios» a la culpabilidad ante la conciencia individual, en soledad total, pero no explícitamente "ante su víctima»; o en estudios dedicados a la sistematización de la culpabilidad, como el de Lacroix.

La actual emergencia del protagonismo social de las víctimas hace incomprensible continuar con esta ausencia, que no solo supone injusticia sino que nos priva de llegar al corazón de la verdad en temas como el de este estudio. Lo expresa muy bien Reyes Mate: «Fundamental para la elaboración de la culpa es la presencia de la víctima. [...] Ella, su sufrimiento, es la respuesta a la naturaleza del acto. Bastaría mirarse en ella para reconocerlo» (Mate, 2013: 17). Lo que me propongo es inspirarme en esta afirmación para desvelar los entresijos de la culpabilidad, siempre con la referencia a la realidad de las víctimas y de quienes han aceptado su culpabilidad por victimarlas.

Este mirarse en las víctimas, que incluye acoger su mirada —con discernimiento cuando se precise-, nos remite a algo que en las vivencias y reflexiones sobre la culpa ha estado muy presente, la mirada, pero en general para ver en ella la opresión propia de la inducción a la culpabilidad. A este respecto, se ha rechazado la culpa identificada como vergüenza ante quien me mira alienadoramente, esto es, me juzga desde una instancia de poder 
considerada totalmente externa a mí, extrañante de mí, humillante e injusta. Pero esta no es la dinámica que propongo. Ahora la elaboración de la culpa comienza en su sentido auténtico cuando es el culpable el que mira a la que ve como su víctima y se mira en ella, en una iniciativa imbricada con la receptividad del impacto del «rostro», en sentido levinasiano, de dicha víctima. Hay, así, otredad pero no externalidad alienadora, pues me conduce a la verdad de mí mismo; hay incluso «autoridad» en la víctima, y hasta mirada de ella, pero no opresora sino justa y liberadora. Es incluso normal, positivo, que haya también vergüenza como componente del sentimiento de culpa, pero, en este marco, como sentimiento moral, positivo.

Una observación antes de pasar a desarrollar el enfoque descrito. Dado que me centraré en esa mirada a la víctima como vía de revelación de lo que es la culpa y de elaboración positiva de la vivencia de culpabilidad, está claro que mi planteamiento no es jurídico, pues el énfasis no lo pongo en la dinámica básica de culpar a otro (la propia del Derecho, aunque no solo de él) sino en la de culparse a sí mismo, aunque con disposición a confrontarse moralmente con la acusación de la víctima. Perspectiva ética por tanto.

Permítaseme, por último, un comentario sobre la objeción a la culpabilidad por su conexión con la religión. Debe reconocerse que su definición y estimulación tiene en la cultura occidental relevantes orígenes judíos, como transformación del sentido del «pecado ante Dios», que la tradición cristiana en parte heredó y en parte reelaboró. El estudio de Ricoeur (1988) lo precisa muy bien. Señala de paso que la otra gran raíz cultural de Occidente, la griega, en este tema no se orientó tanto a la interiorización de la conciencia ética de culpa como a su reasunción según el modelo penal, con un énfasis religioso menor pero no ausente, pues la polis tenía una dimensión sagrada. Ahora bien, que algo se deba rechazar en la cultura pública secular solo porque tiene orígenes religiosos es un prejuicio infundado. Este supondría, además, que se rechazan casi todos los referentes fundamentales de la vida pública: se suelen citar conceptos como el de fraternidad evolucionado en solidaridad; pero el mismo concepto clave de «justicia» tiene esos orígenes, esos trasfondos, por ejemplo, en los profetas judíos. Es decir, de lo que se trata es de mostrar si la categoría de culpabilidad es valiosa para su vivencia no solo religiosa no universalizable sino secular universalizable (haciendo, como en el caso de la justicia, los obligados acomodos, incluyendo ajustamientos críticos), si se precisa para la mejor vivencia de lo humano a nivel personal, intersubjetivo y social. Espero probar que así sucede. De paso, estas consideraciones ponen de manifiesto las dimensiones de particularidad cultural en la reflexión aquí ofrecida; la ausencia, por ejemplo, de los referentes budistas o hinduistas, por citar a los poblacionalmente más relevantes. Pero no tienen vocación de encapsularse en su particularidad, sino de ser una referencia para un potencial diálogo intercultural abierto a aprender del otro y a la mutua interpelación, y teniendo un horizonte compartido de derechos humanos, inculturados en lo que se precise. Paso ya a presentar lo que el enfoque propuesto aporta a la concepción y vivencia de la culpabilidad. 


\section{El DESBORDAMIENTO DE LA SUBJETIVIDAD EN LA CULPABILIDAD}

«La culpabilidad designa el momento subjetivo de la falta», señala Ricoeur (1988: 256). Es la cualidad del sujeto culpable; es connatural vivirla en la interioridad de uno mismo. Pues bien, lo primero que nos enseña la víctima cuando miramos nuestra culpa en ella es que tal afirmación es correcta, pero añadiendo algo clave: la culpa, siendo del sujeto, tiene unos «desbordamientos» de él fundamentales para entenderla bien.

Antes de entrar en ellos aclaremos el momento de la subjetividad. Si la culpa es del sujeto es porque está ligada a un acto que él ha puesto, que es fruto de una decisión suya, del ejercicio indebido de su libertad. En este sentido, está íntimamente unida a la responsabilidad: allá donde hay culpa hay responsabilidad, aunque no necesariamente donde esta existe haya culpa.

En principio, el correlato objetivo de la culpa es la falta en cuanto acción u omisión de la que el culpable es autor. Con todo, Mate, teniendo presente el enmarque de la culpa en la víctima, habla de otro tipo de objetividad, el de las exigencias morales del acto en sí culposo que no quedan anuladas por la autojustificación del sujeto: aunque el crimen no emerja como tal a la conciencia moral o desaparezca de ella, no deja de ser crimen y de marcar como moralmente culpable a quien lo cometió, con todo lo que ello implica (Mate, 2013). Esto es, la inconsciencia no es sinónimo de inocencia. Retomaré esta cuestión con su reenfoque en la problemática de la responsabilidad. Antes, pensando en el momento objetivo de la culpa cabe añadir algo más: inicialmente remite al acto del sujeto; pero, además, a la transgresión de un imperativo moral implicada en él; y, decisivamente, a la persona que con él fue victimada. Es esta progresiva complejidad de la conexión entre momento objetivo y momento subjetivo la que motiva los desbordamientos de este.

Comencemos por el primero. La culpabilidad interior sentida se expresa muy bien con la metáfora de la «carga»: nos pesa. Nos pesa, precisa Ricoeur, porque es resentida "como una disminución íntima del valor del yo» (Ricoeur, 1988: 257). Observación importante, porque nos revela una realidad que, además, puede estimularnos a la búsqueda de transformación personal. Pero cuando elaboramos la culpa ante la víctima, comprendemos que la sola ubicación en la experiencia interior es egocéntrica, y somos invitados a resituarla en la desvaloración que hemos hecho a la persona afectada. La insatisfacción con nosotros mismos, típica de la vivencia de culpabilidad, debe ser eco de la insatisfacción primaria por lo causado a la víctima, desbloqueando así el narcisismo de la culpabilidad. Hay aún más. La vivencia de la carga se experimenta inicialmente como experiencia de opresión interior, a la que podemos responder con la tentación de negar la culpa que la ocasiona acudiendo a excusas ex-culpatorias múltiples. Si miramos a la víctima, comprenderemos lo profundamente injusto del obrar de ese modo, y, además, se nos abrirá una pista para liberarnos de la carga por otra vía, ahora positiva, que pasa por acoger a quien hicimos daño: la del arrepentimiento. 
El segundo desbordamiento se encuentra inicialmente implicado en la conciencia subjetiva de culpa. Se localiza en la norma moral que, incluso concebida autónomamente a la manera kantiana, va más allá de la persona individual. La culpabilidad remite al acto percibido por el sujeto como moralmente indebido porque quebranta lo que considera un imperativo. El sujeto llega a esta conclusión a través de dinamismos interiores que Kant, siguiendo una tradición que él mismo remite a Pablo de Tarso, explica con la antes mencionada metáfora del "tribunal de la conciencia», que estaría innatamente incorporado al ser humano (Kant, 1988). Implica, nos dice, una especie de desdoblamiento interno entre el yo como sujeto de legislación moral por el que me someto a la ley que - como representante de la humanidadme confiero a mí mismo, y mi alter ego de individuo sensible dotado de razón, a la manera de acusador y defensor, con un juez interior que pronuncia el veredicto de absolución o condena. La propuesta está impregnada de un fuerte rigorismo: hay que guiarse por una escrupulosidad extrema, hay que resolver la sentencia según el rigor del derecho, y la absolución no implica alegría positiva pues tiene como «premio» únicamente el contento negativo de haber eludido el peligro de ser considerado culpable.

No entro a analizar esta teoría, discutible en más de un aspecto, y me limito a apuntar de momento la oportuna observación de Bilbeny (1994) de que las duras críticas que después se le hacen presuponen un desplazamiento de la pregunta: del ¿en qué consiste la conciencia? al ¿de dónde viene? Ahora bien, más allá de la desmesura kantiana o la oportunidad de la metáfora y de esas críticas, lo que corrobora la concepción y elaboración de la culpa mirando a la víctima es que se impone un juicio interior evaluativo del acto culposo, una autoinculpación. Y lo que añade al desbordamiento de la subjetividad en la norma, es que ya no se expresa en la forma primaria de "soy culpable de haber quebrantado el imperativo» sino en la de «soy culpable de haber dañado injustamente a esta persona y ella me lo revela».

Que contemporáneamente se pasa de preguntarse qué es la conciencia a cómo se origina, se muestra en una de las citadas objeciones a la culpa. Concretamente, en la que nos habla de un desbordamiento de la subjetividad, pero en una orientación que la referencia a la víctima va a trastocar. La culpabilidad, se dice, no emergería del juicio del tribunal interior, sino del otro exterior que aliena mi espontaneidad: se es culpable no solo ante el otro sino por el otro. Habría desbordamiento de la subjetividad del que siente la culpa en esta intersubjetividad que le abre al otro, pero de forma tal que finalmente, no es uno mismo el causante de la culpa sino que es el otro (o lo otro) (Rodríguez Genovés, 2011), con su imposición normativa, su acusación y su sanción. Ciertamente, en una relación así hay intersubjetividad, pero opresiva —según las pautas de los derechos humanos- para la persona que se siente culpable; lo que no hay es culpa real.

Pues bien, la intersubjetividad en la culpabilidad que nos hace visibilizar la víctima es totalmente opuesta en su dinámica y sentido. Ella enseña al culpable dispuesto a verla, con su sola presencia previa a cualquier acusación, llevada al 
culmen en la presencia radicalmente muda de quien ha sido asesinado, que hay culpa porque la iniciativa del perpetrador estableció con violencia (expresable de múltiples modos y con diversos alcances en su intensidad) una relación interhumana enormemente real: que afectó con su destructividad inmediata a la víctima, pero que, a su vez, como nos recuerda Mate (2013), impactó íntimamente, de modo también destructivo de su interioridad, al victimador. Algo que este no descubre más que si elabora su acción desde la culpabilidad asumida; algo, a su vez, en lo que solo se embarca si se mira en la víctima. Esta intersubjetividad, primero, muestra la verdad de la intersubjetividad precedente y, segundo, se expresa como asimetría en doble dirección porque si en el acto culpable aparece inicialmente la relación de dominio victimariovíctima, en la interpelación de esta se muestra, en dirección opuesta, como relación de autoridad y enseñanza moral que, si es acogida, orienta al culpable hacia su sanación.

Volvamos, iluminados por este recorrido, al momento subjetivo explícito de la culpa. Es importante hacerse cargo de que, asumido, implica una imponente transformación de la conexión que el sujeto mantiene con la realidad (a través de procesos diversos que aquí no entro a analizar): lo que pudo interpretar como acto lícito o incluso heroico (por ejemplo, en la violencia de motivación política que se autojustifica) pasa a percibirlo como acto abominable; las consecuencias del acto que antes veía positivas pasan a ser negativas y, además, emergen en primer plano otras consecuencias reprobables con las que no contó; la concepción y vivencia de la relación con la persona dañada sufre una convulsión; la estima de sí mismo entra en crisis en la conciencia de ser el agente causal de mal.

\section{LA PURIFICACIÓN DEL SENTIMIENTO DE CULPA}

El que la culpa sea del sujeto se confirma en este cuando tiene conciencia de culpa, del disvalor de su acción. Pero dado lo que, según se ha visto, esto implica, tal conciencia está ineludiblemente acompañada de un sentimiento de culpabilidad. Así como la conciencia es dirigida inicialmente al acto de la persona, el sentimiento impacta a la persona como tal. De ahí su fuerza y sus riesgos. Es lo que paso a abordar, aunque advirtiendo con Scheler que la culpabilidad es inicialmente la cualidad del sujeto culpable, que el sentimiento que la asume no es lo primario, «de manera tal que, se sienta uno culpable o no, la culpa permanece» (Scheler, 2007: 42), por lo que el arrepentimiento no tendrá que dirigirse al sentimiento sino a la cualidad objetiva del sujeto, aunque este la haga suya «sintiéndola».

Castilla del Pino (1968) señala que el sentimiento primario o «natural» de la vivencia de culpabilidad es el de "pesar», que el culpable experimenta sobre todo «el peso» de la culpa cometida gravitando sobre su conciencia. La angustia, que suele reclamarse como lo más propio de ella, ligada como tal a una cierta inconcreción —en este caso por la impotencia para deshacer lo hecho—, es 
sentimiento segundo y no propio que, añado, puede estar también relacionado, si la culpa no es manifiesta, con un miedo difuso a que nos descubran, o con la necesidad también difusa de tener que asumir un castigo. Como sentimientos segundos, cabe citar además los de preocupación y tristeza.

Ya en esta primera consideración puede constatarse la incidencia del mirarnos en la víctima para purificar moral e incluso psíquicamente el sentimiento de culpa. Pide que nos preguntemos cuál es su foco, su referencia primaria: ¿la desvalorización del yo o el daño a la víctima? La purificación pasa así por el descentramiento de la referencia a uno mismo, no para arrinconarla sino para resituarla.

Freud (1980), con su enfoque dominantemente genealógico del análisis sobre el sentimiento de culpabilidad, lo conexiona fuertemente con la necesidad de castigo. Nietzsche nos había advertido al respecto que la amenaza de ser castigados no solo no lo estimula, contra lo que suele pensarse, sino que lo bloquea. Pero Freud afina distinguiendo dos orígenes en este sentimiento: el miedo a la autoridad externa, para el que, añado, vale la crítica de Nietzsche, y el temor a la autoridad interiorizada del superyó (la conciencia moral real para él), que autoimpone internamente el castigo no solo por lo que hacemos sino por lo que deseamos. El sentimiento de culpabilidad propiamente dicho, advierte, hay que situarlo en el segundo caso, de gran impregnación: porque podemos tener renuncia instintual en los actos que satisfaga a la autoridad externa y aquiete el sentimiento, pero nunca la logramos en los deseos.

Mirarse como culpable en la víctima aporta una tercera referencia de autoridad, frente a esas dos: la propia víctima. Imagino que el enfoque psicoanalítico la acabaría remitiendo al superyó, como remite este a la interiorización de lo que inicialmente se nos muestra exterior - lo que le daría un sustrato de alienación-. Sin embargo, la víctima, en su pura presencia de estar ahí ante mí causada por mí, develándome lo que de verdad he hecho y sus consecuencias, es autoridad propia frente a mí, con su nítida alteridad, en la que el imperativo de respeto adquiere consistencia "carnal» singularizada; pero a su vez autoridad que no me es extraña, porque encuentro mi huella en ella, de mal pero mía, afectada por mí y yo por ella —en forma éticamente contrapuesta—. ¿Es autoridad que reclama castigo? La víctima que toma la iniciativa puede demandarlo, y tener como referencia el Derecho penal retributivo, o puede plantear otras exigencias en la línea, por ejemplo, del enfoque restaurativo de la justicia (Etxeberria, 2014a y 2018), lo que habrá que acoger en el correspondiente diálogo. Pero creo que siempre se mantendrá algo original decisivo en su presencia desnuda interpelante, posibilitando en el culpable, como condición necesaria aunque no suficiente, un sentimiento de culpabilidad no alienante y muy afinado psíquica y éticamente, en el que culparse no es identificado con autocastigarse aunque implique un cierto tipo de sufrimiento.

En torno a esta ligazón de la culpabilidad con el castigo, Nietzsche (1994), de forma crítica (como «mala conciencia» que se estimula con la creación del Estado para domesticar los instintos del animal humano), hace un apunte importante. Entiende que está comandada por las relaciones mercantiles, en 
las que «se miden» las personas, entre acreedor y deudor. El delincuente es el que quebranta el contrato de vida en común, por lo que queda en deuda con su acreedor, la comunidad. El sentimiento de culpa es, propiamente, el sentimiento de hallarse en deuda. ¿Y cómo se compensa esta? Con el sufrimiento, en el que el perjudicado encuentra un "extraordinario contra-goce»" con el que se siente pagado. Él se remite más expresamente al castigo que se impone al delincuente a través del Derecho, pero Freud, como se ha visto, se encarga de interiorizar la dinámica. Lo que quiero resaltar es que también en la interioridad del culpable puede funcionar el modelo retributivo, puede autoasignárselo e imponerse el autosufrimiento como moneda de cambio con la que saldar su deuda vista como heterosufrimiento. Versión negativa por lo profundamente autocentrada y pretendidamente autosuficiente; los procesos de desculpabilización tienen que abrirse a la víctima y no se someten a cálculos aritméticos.

Estos enfoques punitivos y mercantiles pueden dar pie a una deriva morbosa del sentimiento de culpa, a la que se refieren muchas críticas a él como si fuera la única posible. Pero ya el propio Freud (1980) distingue entre remordimiento «normal», el que se expresa con claridad en la conciencia, el que se tiene tras haber cometido una falta y a consecuencia de esta y presupone disposición a sentirse culpable, al que propone llamar «consciencia de culpabilidad», y el que le interesa como psicoanalista e indagador de la génesis de la conciencia moral, el «sentimiento de culpabilidad» en su expresión más cruda. Traduzco esto por mi parte en la propuesta de que no se trata de acabar con este sentimiento, sino de purificarlo, incluso de transformarlo cuando sea preciso. Castilla del Pino propone a este respecto conseguir que no se exprese en modos e intensidades tales, que él interpreta como «sobreconcienciación» de la culpa, que provoquen en el culpable una fijación en el pasado, «en lo que hubiera podido ser si hubiera efectivamente hecho lo debido» (Castilla del Pino, 1968: 65), no viviendo la culpa sino para la culpa, bloqueando la resolución de ella. Esto supone que no se rechaza el sentimiento como tal, sino su mala expresión; que se propone que incluya una inculpación de sí mismo que desvela una carencia, pero que a la vez estimula la reasunción de responsabilidades y la restauración del yo. Lacroix, teniendo presentes los análisis de Nabert, señala que «el sentimiento de culpabilidad bien comprendido es el lugar por excelencia de la creación continuada del yo por el yo» (Lacroix, 1980: 74).

Pues bien, la referencia adecuada para una purificación así del sentimiento de culpa vuelve a ser la víctima. Para empezar, corrige la afirmación que acabo de citar: puede ser el lugar de recreación del yo, no meramente por el yo sino por el yo orientado hacia la víctima. Mirarse en esta confirma que el sentimiento es lo que tiene que acompañar espontáneamente a la conciencia de culpa: ¿cómo, si esta lo es ante la víctima, va a ser conciencia no acompañada por él?, ¿cómo cabe no sentir pesar, dolor, tristeza ante la víctima?, ¿cómo no vivenciar ese sentimiento como estímulo para su reconocimiento y reparación? Estas son las inquietudes primarias que el centramiento en la víctima evoca. La restauración del yo vendrá como su consecuencia, implicando la reconfiguración de la memoria del pasado por el arrepentimiento en modos que abra al futuro. 
4. Resituación de las VARIABLES DE LA MORALIDAD DE LOS ACTOS EN LA CONCIENCIA DE CULPA

Una condición importante para trabajar adecuadamente el sentimiento de culpabilidad es que tenga como correlato una conciencia de culpa que responda a la realidad de esta, que, por su propia naturaleza, admite grados. Esto a su vez remite a diversas variables que se ponen en marcha en los procesos de decisión que abocan a la acción culposa: la voluntad que se decide lo hace en vistas a un fin, tiene una intención; ahora bien, a la hora de ejecutar la acción, de realizar el proyecto, el sujeto se encuentra con unas circunstancias favorables o adversas; y la acción que lleva a cabo no se cierra en sí misma, tiene unas consecuencias. Los subrayados marcan las cuatro variables que inciden en la moralidad, también, por tanto, en la culpabilidad. En torno a ellas nos encontramos con el clásico enfrentamiento entre éticas que privilegian la intención, como la kantiana, y éticas de las consecuencias, como las utilitaristas. $\mathrm{O}$, para utilizar la terminología de Weber, con su propio enfoque, éticas de la convicción y de la responsabilidad. No pretendo entrar aquí en ese debate. Centrado en el objetivo de estas líneas es suficiente con que formule los interrogantes que aparecen al relacionar entre sí las variables, y mostrar luego que la referencia a la víctima es la más adecuada para afrontarlos y discernir así la culpabilidad subjetiva. Los interrogantes son al menos estos:

a) Es generalmente compartida la tesis de que el sentido subjetivo de la acción moral se encuentra en la intención. Lo que significa que la intención mala hace per se culpable a quien la tiene. Pero cabe preguntarse: ¿incluso aunque el acto al que aboca sea materialmente bueno?, ¿incluso aunque siendo malo tenga consecuencias buenas?

b) Puede darse una intención subjetivamente buena pero objetivamente mala: ¿hace buena la acción objetivamente mala en la que coherentemente esa intención se realiza?, ¿hace no culpable a quien la tiene y la realiza?, ¿depende esto del grado de responsabilidad, en el sujeto, de su ignorancia?

c) Una intención subjetivamente buena y con fundamento moral ¿hace bueno al acto imprudente que acarrea consecuencias malas?, ¿hace no culpable a quien la tiene y la efectúa?

d) ¿Hasta qué punto las circunstancias obstaculizadoras de la realización de actos buenos con intención buena que se imponen, diluyen la culpabilidad de quien acaba no haciéndolos?, ¿depende de la consistencia objetiva del contexto y/o también de la consistencia subjetiva del agente potencial?

Cuando se tiene como referencia la mera ley moral, estos interrogantes se convierten con frecuencia en vía para introducirnos en casuísticas a veces tramposas. Cuando la referencia son las víctimas, en primer lugar, todas las preguntas se muestran necesarias en vistas a ellas y no solo al sujeto potencialmente culpable y, en segundo lugar, se perciben necesarias no solo para faltas menores - por ejemplo, una «mentira piadosa»-, sino, 
especialmente, para faltas mayores, como la violencia asesina de motivación política. No puedo extenderme aquí en la proyección detallada de estos interrogantes a problemáticas precisas de culpabilidad como las que acabo de citar. Permítaseme, por eso, que me limite a marcar los criterios generales para abordarlas desde las víctimas, añadiendo en algún caso pequeñas ejemplificaciones:

a) Quien tiene intención global de moralidad debe estar atento a integrar todo lo posible las cuatro variables en su versión buena. Es el mejor modo no meramente de no entramparse con la culpabilidad sino de no victimar, requisito prioritario de la iniciativa moral. Hay que reconocer, con todo, que en ocasiones aparecen tensiones entre las variables, que piden acudir a criterios complementarios como los que siguen.

b) La intención buena debe ser vista como condición necesaria pero no suficiente de moralidad. Una intención buena gestionada mal, por ejemplo, con imprudencia — en la que cabe situar la culpabilidad-, puede generar víctimas. La víctima puede considerar la falta de intención de mal como atenuante, y orientarse con más facilidad al perdón, pero lo que toca prioritariamente al culpable es asumir ante ella su responsabilidad e incluso culpabilidad, si hubo negligencia.

c) En la intención mala hay ya culpabilidad, aunque las circunstancias hagan que aboque a una acción que tiene consecuencias buenas. La intención mala decisiva se expresa como intención de hacer daño.

d) Caben intenciones buenas o no inmorales en sí (p.e. que expresen fines de justicia social o de derechos de soberanía de la nación) que se utilizan para justificar acciones en sí malas que son consideradas medios necesarios para esos fines (incluyendo el asesinato, como en las violencias de motivación política). En el recurrente debate de si el fin justifica los medios, la referencia clave deben ser de nuevo las víctimas, que evidencian que ningún fin queda justificado cuando es a costa de ellas, y que enseñan además que cuando son así instrumentalizadas los fines justificatorios aducidos quedan pervertidos. Mientras el sujeto se autojustifica de este modo, él no se considera culpable, no tiene sentimiento de culpabilidad, pero ello no evita que la acción sea culpable y que haya en él un deber de lucidez moral ante el que ha fallado, como se le mostrará cuando se mire en la víctima y se deje mirar por ella. Conseguida esta lucidez, le tocará asumir la correspondiente culpabilidad y responsabilidad por el mal causado. Y expresar un dolor, centrado en quien dañó y ante él, que presupone una culpabilidad ex post (extraña para la racionalidad fría pero manifiesta para la razonabilidad que integra al dañado) ante su intencionalidad inicial: «¡cómo pude ser tan ciego!». Ello le hará percibir además que ex-culparse ante la víctima por la intención que tuvo solo supone acrecentamiento injustificado de la victimación de esta.

e) Frente a las circunstancias adversas, de dificultad o riesgo, para realizar acciones buenas con buena intención, además de la atención prudencial 
a las consecuencias, hay que tener la intencionalidad añadida de incorporar en la manera de ser de uno mismo las virtudes de la valentía, la constancia y la fortaleza. Este puede ser el caso de acciones cívicas con las que enfrentarse a los violentos de motivación política, que se nos imponen por solidaridad con las víctimas. Tal intencionalidad es también una referencia para el discernimiento de la culpabilidad.

\section{COMPLEJIZACIÓN DE LA RESPONSABILIDAD EN EL MARCO DE LA LABILIDAD HUMANA}

Esta revisión de las variables de la culpabilidad tiene una importante consecuencia en la asunción de responsabilidades morales, en parte ya sugerida. Normalmente, se tiende a pensar que allá donde el sujeto no percibió culpabilidad porque entendía que obraba con buena intención, poniendo acciones que pensaba que estaban justificadas y que no iban a tener consecuencias negativas, no tiene realmente culpabilidad y tampoco, por tanto, la responsabilidad correspondiente. Ahora bien, ya en la moral clásica hay un elemento que debe ser tenido en cuenta: el de si esa ignorancia en cada una de las tres variables es culpable — debida a la indolencia o incluso resistencia ante el conocimiento moral y el de la realidad en la que se inserta la acción-; en tal caso hay culpabilidad en la intención, la acción o las consecuencias, con la correspondiente responsabilidad, ante las víctimas en especial, por los daños que se les han causado.

Pero hay algo más. Incluso cuando la ignorancia es no culpable, en una persona moralmente sensible, cuando descubre que su intención-acción ha supuesto de hecho victimación, la autoasignación de culpabilidad/inocencia pasa a un segundo plano, y lo que le importa es que fácticamente ha victimado, lo cual le empuja a responsabilizarse de ello a fin de colaborar todo lo posible en la restauración de quien victimó. Por ejemplo, unos padres que tratan honestamente lo mejor que saben a un hijo con discapacidad intelectual, pero de forma que objetivamente supone que le tratan mal porque no le respetan, aunque hayan actuado con ignorancia no culpable, cuando lo descubren porque reciben orientación y ayuda externa, no deben alimentar un sentimiento de culpabilidad que les torture y les paralice, pero será muy positivo que experimenten un sentimiento de dolor que les incentiva a focalizarse en su hijo victimado, a ofrecerle la atención que merece, restaurando todo lo posible los daños causados, «respondiendo» ante él. En esta autorresponsabilización se encuentra precisamente la prueba de su desculpabilización subjetiva.

El centramiento en las víctimas nos hace ampliar el ámbito de la responsabilidad también desde otras tres perspectivas. Primero, somos responsables de acoger a las que no son víctimas de nuestra iniciativa culpable en la medida en que necesitan esa acogida de nosotros y está en nuestro poder; aquí la responsabilidad precede a la culpabilidad, que adviene solo si se falla en la primera. Segundo, nuestra responsabilidad estrictamente subjetiva por 
nuestra falta moral puede agrandarse por el marco en el que la hemos cometido. Lo aclaro con un ejemplo: exmiembros de ETA que se han arrepentido, asumen con coherencia moral que no solo son responsables de las víctimas directas que ellos han causado; son también corresponsables de las victimaciones que ocasionó la organización terrorista en la que se insertaron y a la que apoyaron activamente, así como de los daños políticos a la democracia y la convivencia cívica que todo ello supuso. ${ }^{4}$ Tercero, como nos advierte Reyes Mate, tenemos que abrirnos también - mirando a las víctimas-a las responsabilidades heredadas deslindables de las culpabilidades, por delicado y complicado que pueda ser gestionarlas:

Nacemos con una hipoteca o responsabilidad que no derivan de actos nuestros sino del tiempo y el lugar en el que nos insertamos. La patria en la que nacemos tiene una deuda - un patrimonio material y espiritual construido sobre el sufrimiento de otros- que tenemos que asumir y que por eso condiciona nuestra libertad. Deuda por lo que hemos tomado indebidamente de las generaciones anteriores y duelo por los sufrimientos sobre los que se ha construido nuestro bienestar son los nuevos componentes de una concepción moral de la democracia (Mate, 2011: 237-238).

Un panorama como este de posibilidades de culpabilidad y responsabilidad puede mostrarse abrumador. Parece que da razón a las críticas que postulan que la categoría de culpa como tal solo sirve para aplastarnos. Pero, primero, siempre tenemos que plantearnos la cuestión prioritaria de si tal panorama es condición de posibilidad de la justicia debida a las víctimas, y pienso que estamos mostrando que así es, y, segundo, creo que ya se va intuyendo que la ajustada conciencia de culpabilidad, con su correspondiente sentimiento, es la base sólida para la sanación del culpable, que el reconocimiento pleno de su responsabilidad es también la vía para construirse positivamente a sí mismo y colaborar en la construcción social, que la auténtica y consistente estima de sí es la que se asienta en la verdad, adecuadamente asumida, de todo el entramado de relaciones interhumanas en que nos encontramos.

Pensar en la sanación de la culpabilidad aboca al arrepentimiento. De todos modos, antes de entrar en este tema, para ajustar más la cuestión de la responsabilidad, conviene destacar que hay dos modos de entender la consistencia subjetiva del acto culpable, muy bien expresados por Ricoeur (1988): el de la visión ética del mal, la kantiana; y el de la asentada en el reconocimiento de la labilidad humana, la suya propia, a la que me adhiero.

En la visión ética del mal, este se nos muestra como una máxima del libre albedrío. Es fruto de un movimiento de la libertad que lo toma sobre sí, considerándose responsable de él, que lo ve como mal cometido por ella, que reconoce que dependía de ella el que no hubiera sido. Hay aquí una grandeza:

4 Se conexiona también con esto, aunque desbordándolo, la ya clásica reflexión de JASPERS (1998) sobre la culpabilidad, distinguiendo en el ciudadano cuatro culpabilidades: criminal, política, moral y metafísica 
en la confesión de la falta se descubre la potencia de la libertad. Puede verse una anticipación de esta visión - con sus diferencias- en la descripción que el autor hace del enfoque fariseo de la culpabilidad, algunos de cuyos rasgos son: una concepción de la libertad enteramente responsable y siempre disponible para ella misma, con lo que la imputación personal por el mal es plena; el mérito y su recompensa que acompañan al justo frente al demérito del injusto, que reclaman una nítida separación entre ellos; la ritualización y juridificación de la vida moral. Estando además, pero como degeneración del modelo, la hipocresía.

Con todo, observa Ricoeur, una concepción ajustada del ser humano mostrando su labilidad constitutiva, así como la simbólica del mal, dando que pensar, descubren los límites de esta visión ética del mundo. La labilidad humana supone que «la posibilidad del mal moral está inscrita en la constitución del hombre»; «designa la región y la estructura de la realidad que por su menor resistencia ofrece un "lugar" al mal» (Ricoeur, 1988: 149 y 159). Su posición de mal puede ser comprendida a partir de esta labilidad que, por la fragilidad que implica, lo hace posible. Pero la labilidad remite también a capacidad:

Decir que el hombre es lábil es decir que la limitación propia de un ser que no coincide consigo mismo es la debilidad originaria de la que procede el mal. Y con todo, el mal no procede de esta debilidad más que porque se pone. Esta última paradoja es el centro de la simbólica del mal (Ricoeur, 1988: 162).

Pues bien, es tras realizar la hermenéutica de esta simbólica primaria del mal (la mancha, la caída, la cautividad, con sus relatos míticos) y explorando cómo da que pensar, como Ricoeur postula lo que llama el siervo albedrío, la paradoja de un libre albedrío cautivo. En él se nos muestra que la interioridad de la culpabilidad no lo abarca todo, pues está también la seducción: aunque puesto, el mal es lo que atrae, lo cual supone que no existe el malvado absoluto. El mal es a la vez puesto y siempre ahí, en alguna manera "sufrido». Pero la seducción es en último extremo auto-seducción, el mal seductor es mal de un ser humano que sigue siéndolo. En este sentido no es el sustituto de la bondad humana sino «su oscurecimiento, la desfiguración de una inocencia, de una luz y una bondad que permanecen. Por radical que sea el mal no es tan originario como la bondad» (Ricoeur, 1988: 306).

Que no exista el malvado absoluto, que su responsabilidad por el mal sea cierta —el momento de poner el mal está ahí-, pero que sea a su vez responsabilidad del tentado, que lo originario es la bondad, esto es lo que aquí se subraya. Es lo que, creo, respondiendo a la verdad del ser humano, asienta con más realismo sus posibilidades de restauración. Es lo que perciben las víctimas que se acercan a quien las ha victimado, incluso mediando un asesinato, por ejemplo, del esposo o el padre como he podido constatar en víctimas de ETA, cuando acogen e incluso alientan procesos de arrepentimiento del victimario en la convicción de que tienen que darles «una segunda oportunidad». 


\section{DinÁmicas no MERCANTILES DEL ARREPENTIMIENTO}

El análisis de la culpabilidad centrado en la víctima aboca ineludiblemente al arrepentimiento - le es debido a ella-, y a la vez resulta sanador para el victimario. Se vivencia como desarrollo intrínseco de la autenticidad de la culpabilidad. Pero también aquí nos encontramos con rechazos nítidos de él.

Un crítico contundente es Spinoza. «El arrepentimiento — nos dice en la proposición LIV de su Ética - no es una virtud, o sea, no nace de la razón; el que se arrepiente de lo que ha hecho es dos veces miserable e impotente» (Spinoza, 1987: 306). Ofrece dos tipos de argumentos. El primero parte de que la esencia del alma afirma solo aquello que es y puede; quien se conoce según la razón conoce su esencia, esto es, su potencia, y se alegra; el arrepentimiento, en cambio, como la humildad, es una tristeza que brota de quien considera su impotencia, lo que no se debe a que se conoce sino a que su potencia de obrar está reprimida. El segundo argumento parte de la definición de arrepentimiento como «tristeza acompañada por la idea de algo [considerado malo] que creemos haber hecho por libre decisión del alma» (Ibid. 241). Ahora bien: a) eso se sustenta en una creencia en la libertad muy vehemente pero no fundada - recuérdese su tesis determinista en la que la libertad se plasma solo en la coincidencia querida con el curso necesario de las cosas-; b) hay un gran relativismo social sobre lo bueno y lo malo que hace que cada uno se arrepienta o gloríe de sus acciones según ha sido educado.

Hoy cabe detectar ecos spinozianos en el enfoque orientalizante del rechazo al arrepentimiento (estoicismo y spinozismo pueden verse como la versión occidental del budismo). En ellos se nos enfatiza que lo importante no es lo que fuimos sino lo que somos en cada momento del presente, en el que tenemos que centrar nuestra energía. También pueden encontrarse conexiones - combinadas con influencias del individualismo liberal- en la afirmación en boga "no me arrepiento de nada», tras la que está el presupuesto de que arrepentirse implica disminución de nuestra consistencia personal.

Evidentemente, en un marco determinista el arrepentimiento no tiene sentido. A lo más, como afirma Spinoza, es algo a lo que es bueno que se incite al vulgo, a los hombres de ánimo impotente, para que se garantice, con el temor que según él implica, la unidad social. No entro aquí en el debate de los supuestos de este autor. Solo quiero subrayar que quien defiende su tesis debe confrontarse con la inmensísima victimación que nos causamos los humanos —que Spinoza no explicita—: frente a ella la serena alegría contemplativa del sabio ante el todo que es necesariamente, resulta muy problemática; y el rechazo del arrepentimiento, no identificándolo con temor al castigo ni con la quiebra de la consistencia personal, sino con el dolor por haber causado daño a alguien, se muestra mucho más difícil de lo que se supone. Por cierto, a propósito de la concepción del arrepentimiento como desarrollo del temor, Scheler (2007) observa oportunamente su inconsistencia: quien teme mira al futuro para evitar algo, bloqueando o contaminando la mirada al pasado necesaria para arrepentirse. 
También se desmonta el arrepentimiento en la consideración nietzscheana de la culpa en el marco de un contrato mercantil, a la que ya me referí y que conviene reiterar: la culpa es una deuda (con Dios, con la sociedad), y la moneda con la que hay que pagarla es el sufrimiento. En este contexto, el arrepentimiento solo puede ser visto como sufrimiento personal expiatorio y como incitador de castigos complementarios (autoimpuestos o heteroimpuestos - Derecho-). Las víctimas, ahora, solo aparecen colateralmente en una aplicación de la justicia acorde con la ley del talión, en cuanto que hacer sufrir "produce bienestar en sumo grado, en la medida en que el perjudicado cambiaba el daño, así como el desplacer que este le producía, por un extraordinario contragoce: el hacer-sufrir, una auténtica fiesta» (Nietzsche, 1994: 74-75). Además, se cierne una amenaza: la deuda puede mostrarse impagable y la culpa, por tanto, inextinguible, con lo que se eterniza la autotortura. Esta sería la condición de la culpa ante Dios, pero, tras su muerte, es reasumida socialmente, con lo cual todo es «de una tétrica, sombría y extenuante tristeza» (Ibid. 106). ¿Cuál es la solución que propone Nietzsche? El olvido, sin el que no hay jovialidad, ni novedad, ni presente. El olvido como forma de salud vigorosa frente a la memoria.

Ciertamente, arrepentirse es memorar con otro sentido moral el acto culpable que se realizó; y puede hacerse de tal modo que resulte paralizador. Es también sentir dolor estimulado por ese acto; que puede vivenciarse como casi pura expresión de masoquismo o como puro pago mercantil. Pero con esto solo apunto a que caben versiones morbosas de él que tienen su contrapunto en la versión sana originaria. En cuanto a la alternativa del olvido, primero, es fácil de decir pero no de vivir, porque un daño culpable grave, por poca sensibilidad moral que se tenga, deja una profunda huella, perenne de algún modo; aunque haya que aspirar a que sea a modo de cicatriz que, mediando el arrepentimiento, expresa la curación. Y segundo, si nuestra referencia moral son los derechos humanos, tal olvido implica por él mismo una injusticia con la víctima y potencia otras.

Esto conduce a la tarea de reconvertir la crítica nietzscheana en reto para purificar el arrepentimiento; lo que se logra si se vive «mirándose en la víctima». Cuando así sucede, el dolor originario es motivado por el daño que le causamos; y, concomitantemente, por el que nos hemos causado en nuestro modo moral de ser. Por supuesto, no es dolor por las consecuencias negativas que la falta realizada puede acarrear a nuestros intereses; ni siquiera, prioritariamente, vía para lograr la paz con nosotros mismos, de nuevo efecto concomitante que podemos esperar, más que fin per se. Lo central deja de ser el sufrimiento personal, y pasa a serlo la firme voluntad de no repetición del mal, la reparación y la colaboración en la restauración de la víctima. En este sentido el arrepentimiento es motivación ética, emocionalmente densa, para la responsabilidad y para la realización efectiva de esta. Por ello precisamente no se nos presenta como sustituta de él sino enmarcada en él.

Se evidencian así, como inauténticos, modos mercantiles y estratégicos de arrepentimiento. Este no es un pago a través del sufrimiento, porque no 
responde a una deuda en sentido comercial (no está en juego lo aritméticamente contabilizable). Sabemos que se lo debemos a la víctima, pero no se nos ocurre considerarlo como contrapartida de su perdón que estaría obligada a concedernos. No nos arrepentimos para que nos perdonen, sino aunque no nos perdonen, con disposición incluso a comprender el rechazo. El arrepentimiento queda plenificado cuando es acogido en el perdón del otro, pero esta es una experiencia de gratuidad. Es lo que se nos muestra, como contrapunto, en la justicia penal: un delincuente puede reconocer su culpa (jurídica), aceptar su castigo carcelario y decir al salir de la cárcel sin un ápice de arrepentimiento: he cumplido mi deuda, incluso "he expiado», no debo nada a nadie.

Centrarse así en la víctima —en la escucha de la voz que nace de su victimación- no tiene por qué suponer vivenciar un remordimiento perpetuo ante lo absolutamente irreparable, significado en el mito de Caín, que expresaría solo él el orden moral y que se contrapondría al arrepentimiento (Sánchez Ferlosio, 1996). Únicamente si este es asociado con la expiación, la indemnización, el orden jurídico del intercambio — como hace este autor-se puede llegar a esa conclusión. Pero arrepentirse de verdad no es eso; definido como acabo de señalar, nos libra de la desesperación del remordimiento anclado en el pasado, egocentrado a pesar de lo que parezca a primera vista y paralizador de iniciativas de esperanza hacia y, si es posible, con la víctima.

Para avanzar en lo dicho hasta ahora sobre el arrepentimiento, vuelvo a su conexión polémica con el pasado, guiándome con cierta libertad por las reflexiones de Scheler (2007). Mira ineludiblemente hacia atrás, nos dice, pero actúa hacia delante. Aunque nada puede «sacar del mundo» la materialidad de la acción culposa que hemos hecho ni sus consecuencias causales, siempre podemos preguntarnos, mientras vivimos, qué hacer con nuestro pasado, siempre estamos abiertos a completar o transformar el sentido de nuestras vivencias de él (también sobre esto Rueda, 2012). A este respecto, en el recuerdo anida una libertad significativa frente a la dura facticidad del acontecimiento que protagonizamos. Arrepentirnos es precisamente volvernos sobre un momento de nuestra vida pasada con la intención precisa de imprimirle un nuevo sentido: el de su consideración como mal, con el correspondiente rechazo valorativo; de este modo, a través de él expresamos el poder de nuestra libertad. Ahora bien, al hacer esto no nos arrepentimos sin más de la acción, sino de nuestro modo de ser que la propició en ese pasado. Tal intención de veracidad sobre nosotros solo es posible con la disposición al arrepentimiento y este, a su vez, no es viable sin humildad. El pasado así retrabajado revierte como fuerza motriz hacia el futuro, como movimiento para neutralizar la eficacia de la culpa, para expulsarla del núcleo de la persona salvando a esta. Que no se propone sin más otro modo de actuar, sino la transformación de sus disposiciones, que puede vivenciarse como «conversión» o renacimiento en culpabilidades especialmente graves.

Hasta aquí la apretada síntesis de la fenomenología del arrepentimiento hecha por Scheler. Aporta matices relevantes. Pero muestra una laguna seria: todo lo que se describe sucede en la conciencia del culpable enfrentado 
a su culpa. Hay que suponer que en ella está implicada la víctima, pero no aparece, no es referencia real para la transformación que deba hacerse y la responsabilidad que deba asumirse. Lo que estoy proponiendo frente a ello, es que la mirada introspectiva se abra a la transitividad: mirarse en la víctima; revisar el sentido del pasado de culpa y transformar el presente abierto al futuro con esta dinámica más compleja que la incorpora, abierta a su protagonismo.

Cuando esto sucede, la eficacia del arrepentimiento para borrar la culpa se complejiza. Scheler afirma con contundencia que con él el sujeto la expulsa del núcleo de su persona, salvándose moralmente, que la mata definitivamente. Pero, por ejemplo, Reyes Mate, al incluir ese mirarse en la víctima y mirarla, no lo ve tan sencillo. Suele señalarse que el arrepentimiento implica una confesión de un modo u otro. Ahora habría que añadir que tiene que ser confesión ante la víctima, en forma de petición de perdón. Con lo que aparece la dinámica entrecruzada, moralmente asimétrica, de arrepentirse y perdonar. Ante la que Mate afirma: la liberación de la culpa «no ocurre en recompensa por el arrepentimiento, sino por libre y graciosa iniciativa de quien es objeto del daño [...] El perdón libera al criminal de su atadura al acto cometido y por ello inaugura un nuevo comienzo» (Mate, 2011: 235). Pienso que tomada en toda su contundencia es una tesis discutible: el arrepentimiento sincero e implicativo de lo que se ha señalado, tiene un efecto sanador aunque no sea acogido por el perdón de la víctima, porque ya no está (ha sido asesinada), porque psíquicamente no puede, o porque lo considera negativo. Pero, por otro lado, hay que subrayar que la sanación se plenifica cuando se da. Aunque deba formar parte del arrepentimiento la disposición a aceptar a la víctima que rechaza el perdón.

\section{CONCLUSIÓN}

Con las últimas consideraciones estoy entrando ya en una temática (el perdón y la reconciliación: Etxeberria, 2014b, 2015 y 2018) de la que señalé que me quedaría a las puertas. Concluyo por eso esperando que el recorrido realizado haya evidenciado la tesis que lo ha animado relativa a la fuerza reveladora - para la comprensión-y motivadora - para la realización-de la focalización de la culpabilidad del sujeto en las víctimas, expresión objetiva del mal que causó. Tal focalización, llevada a la práctica, además de completar la justicia debida a la víctima, aporta un doble y valioso beneficio: el culpable restaura su ser moral lesionado y la sociedad recupera a un miembro rehabilitado.

\section{BiBLIOGRAFÍA}

Aramayo, R. R. (2003). "Culpa y responsabilidad como vertientes de la conciencia moral». Isegoría, 29: 15-34. 
Bilbeny, N. (1994). Kant y el tribunal de la conciencia. Barcelona: Gedisa.

Castilla del Pino, C. (1968). La culpa. Madrid: Revista de Occidente.

Cohen, T. R.; Panter, A. T. y Turan (2012), «Guilt Pronenesses and Moral Character». Current Directions in Psychological Science, 21/5: 355-359.

Etxeberria, X. (2012). «Ser y existencia de los derechos humanos». Pensamiento, 68/257: $389-412$.

Etxeberria, X. (2013, 2aed.). «Los encuentros restaurativos como diálogo moral». En Rodríguez Pascual, E. (coord.). Los ojos del otro. Encuentros restaurativos entre víctimas y exmiembros de ETA. Santander: Sal Terrae, 23-32.

Etxeberria, X. (2014a). «En torno a la legitimidad y el sentido del castigo por el delito». Revista Portuguesa de Filosofía, 70/4: 765-786.

Etxeberria, X. (2014b). «La reconciliación cívica como mediación entre el tiempo del conflicto armado y la conflictividad democrática». Revista Colombiana de Bioética 9/2: 11-26.

Etxeberria, X. (2015). «El lugar del perdón en la justicia en contextos de transición política». En Bernuz, M. J. y García, A. (eds.). Después de la violencia. Memoria y justicia. Bogotá: Siglo del Hombre, 99-153.

Etxeberria, X. (2018). El perdón y la reconciliación en la convivencia cívica, Barcelona: ICIP.

Freud, S. (1980). El malestar en la cultura, Madrid: Alianza.

Jaspers, K. (1998). La cuestión de la culpa. Madrid: Tecnos.

Kant, I. (1989). La metafísica de las costumbres. Madrid: Tecnos.

Lacroix, J. (1980). Filosofía de la culpabilidad. Barcelona: Herder.

Mate, R. (2011). Tratado de la injusticia. Barcelona: Anthropos.

Mate, R. (2013). La piedra desechada. Madrid: Trotta.

Nietzsche, F. (1994). La genealogía de la moral. Madrid: Alianza.

Ricoeur, P. (1988). Philosophye de la volonté 2: Finitude et culpabilité. Paris: Aubier.

Ríos, J. (2015). «El valor de la palabra. Experiencia de encuentros restaurativos entre víctimas y exmiembros de ETA». En Bernuz, M. J. y García, A. (eds.). Después de la violencia. Memoria y justicia. Bogotá: Siglo del Hombre, 233-274.

Rodríguez Genovés, F. (2011). «Ética y culpabilidad», El catoblepas. 108. http://www. nodulo.org/ec/2011/n108p07.htm

Rueda, C. (2012). «Perdón y arrepentimiento: la experiencia de Jean Améry». Ideas y valores, LXI/148: 79-99.

Sánchez Ferlosio, R. (1996). «La señal de Caín». Claves de la razón práctica, 64: 2-15.

Scheler, M. (2007). Arrepentimiento y nuevo nacimiento. Madrid: Encuentro.

Schopenhauer, A. (1993). Los dos problemas fundamentales de la ética. Madrid: Siglo XXI.

Spinoza, B. (1987). Ética demostrada según el orden geométrico. Madrid: Alianza.

Universidad de Deusto

Xabier EtXeberria

xetxemau@deusto.es

(Artículo aprobado en diciembre de 2015) ${ }^{5}$

5 Revisado y actualizado para la publicación en marzo de 2020 